\title{
Pharmacotherapy of Systemic Autoimmune Diseases in the Convention of the Covid-19 Pandemic: Search for Innovative Technologies in the Study
}

\section{Ihor Hayduchok*}

Associate Professor, PhD in Medicine, Lviv Medical Institute LLC, Ukraine

*Corresponding Author: Ihor Hayduchok, Associate Professor, PhD in Medicine, Lviv Medical Institute LLC, Ukraine.
Received: July 10, 2021

Published: August 24, 2021

(C) All rights are reserved by Ihor Hayduchok.

\begin{abstract}
The article presents the results of the search for innovative technologies in pharmacotherapy in determining the balance of "supply and demand" for drugs of different clinical and pharmacological, classification and legal, nomenclature and legal groups is timely in a pandemic COVID-19. The aim of the research was to search for innovative technologies for the study of pharmacotherapy of systemic autoimmune diseases by content analysis on the example of drug by the INN Silymarin ATC code A05BA03 in healthcare facilities. Content analysis was performed according to the range of manufacturers by grouping them using the Sturgess formula, followed by construction of discrete series of variations and distribution polygon. The conducted analysis allows obtaining a complete description of the balance of "supply and demand" between the range and manufacturers of drugs approved for use. Doctors have a choice of the appropriate drug and the manufacturer that corresponds to the social personalized pharmacotherapy.
\end{abstract}

Keywords: Pharmacotherapy; Evidence-based Medicine; Evidence-based Pharmacy; Systemic Autoimmune Diseases; Drugs;

Content Analysis

\section{Introduction}

In the current context of the spread of the coronavirus pandemic, the search for innovative technologies in the study of pharmacotherapy of systemic diseases in patients with dual health disorders is growing. Despite numerous publications on COVID-19, currently conceptual thinking of the problem is only in its infancy. Pharmacotherapy of patients with systemic autoimmune diseases during the COVID-19 pandemic is a topical issue. Further analysis of COVID-19 among patients with systemic autoimmune diseases is important [1-4].

Systemic autoimmune diseases are pathological processes that are characterized by the development of a stable humoral or cellu- lar response directed against their own antigens, which leads to the defeat of even the whole organism. Systemic autoimmune diseases are protracted (chronic) due to the constant presence of antigen in the body, because it is a normal component of cells. The etiology of systemic autoimmune diseases is still unclear. Among the systemic autoimmune diseases are systemic lupus erythematosus, systemic vasculitis, psoriasis, rheumatoid arthritis [5-9].

The search for innovative technologies in pharmacotherapy in determining the balance of "supply and demand" for drugs of different clinical and pharmacological, classification and legal, nomenclature and legal groups is timely in a pandemic COVID-19. Today it is important to use effective, quality, safe and available 
drugs for pharmacotherapy of systemic autoimmune diseases. It is important to use innovative technologies on the principles of evidence-based medicine, forensic pharmacy, evidence-based pharmacy, medical and pharmaceutical law [10-14].

The use of innovative experimental technologies in the study of pharmacotherapy of systemic autoimmune diseases in a pandemic of coronavirus infection is a timely and socially oriented scientific task. At the same time, a fair balance between the supply and demand of drugs must be realized. Demand for drugs is formed by patients with systemic autoimmune diseases. The offer is formed by domestic and foreign drug manufacturers. A fair balance cannot be achieved if patients do not receive the pharmacotherapy prescribed by doctor on time [15].

Previously, pharmacoeconomic research in pharmacotherapy of systemic lupus erythematosus and systemic vasculitis was written in articles [16,17].

The need for evidence to inform about the benefits and harms of drugs in pharmacotherapy is becoming increasingly important. In parallel, clinical pharmacology and clinical pharmacy and practice research is evolving. Research evidence should be used to identify new research technologies for improved health service delivery, and rigorously evaluate the use of new drugs in pharmacotherapy. The generation of such evidence through practice-based research should be predicated on appropriate use of robust and rigorous methodologies. In addition to the quantitative and qualitative approaches used in medical and pharmacy practice research, mixed methods and other novel approaches are increasingly being applied in medical and pharmacy practice research. Approaches such as content analysis now find their rightful place in research into drug selection, evaluation of efficacy, benefit and harm to pharmacotherapy regimens [18].

\section{Aim of the Study}

The aim of the research is to search for innovative technologies for the study of pharmacotherapy of systemic autoimmune diseases by content analysis on the example of drug by the International nonproprietary name (INN) Silymarin ATC code A05BA03 in healthcare facilities (hospitals, clinics, pharmacies).

\section{Materials and Methods}

The methodology of content analysis of drugs according to INN Silymarin ATC code A05BA03 was based on theoretical principles of evidence-based medicine, forensic pharmacy, evidence-based pharmacy, medical and pharmaceutical law, clinical pharmacology and pharmacotherapy [19-21].

For the content analysis, the method of drug selection developed by the Department of Medical and Pharmaceutical Law, General and Clinical Pharmacy of the Kharkiv Medical Academy of Postgraduate Education (Head of the Department - Prof. Viktoriya Shapovalova) was used, which included seven criteria [22-24].

Selection criteria for INN Silymarin ATC code A05BA03 to innovative experimental study shown on figure 1.

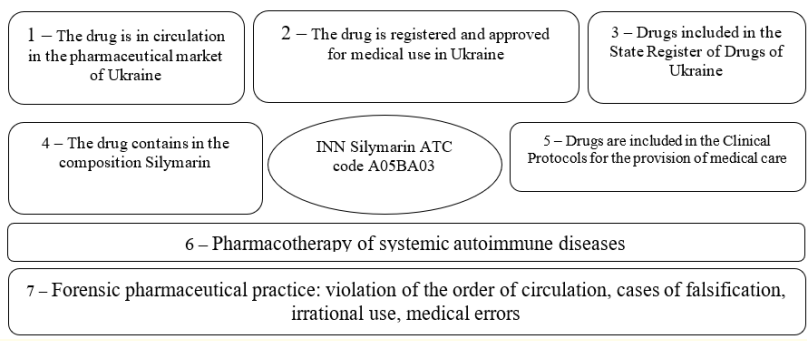

Figure 1: Criteria for selection of drugs according to INN Silymarin ATC code A05BA03 to search for innovative technologies in the study.

Study material - INN Silymarin ATC code A05BA03. All drugs meet six criteria, forensic pharmaceutical practice (seven criteria, Figure 1) is absent as of June 2021. The names of drugs were systematized by INN Silymarin ATC code A05BA03, trade names, range and manufacturers.

Content analysis of INN Silymarin ATC code A05BA03 was performed according to the range of manufacturers by grouping them using the Sturgess formula, followed by construction of discrete series of variations and distribution polygon: $\mathrm{n}=1+3$, 322 $\lg \mathrm{N}$, where $\mathrm{n}$ - is the number of groups; $\mathrm{N}$ - is the number of drugs. The limits of the step of certain groups of drugs were determined by the formula:

$$
h=\frac{X \max -X \min }{n}, \text { where } \mathrm{h} \text { is the step size of the group; } \mathrm{X}_{\max }
$$
- the maximum number of manufacturers; $X_{\min }$ - is the minimum value of the number of producers [22-24]. 
Pharmacotherapy of Systemic Autoimmune Diseases in the Convention of the Covid-19 Pandemic: Search for Innovative Technologies in the Study

Content analysis is a widely used innovative method of analysis of pharmacotherapy schemes for systemic connective tissue diseases. There are three approaches to conduct content analysis: conventional, directed, and summative. All three approaches are used to interpret meaning from the content of text data and, hence, adhere to the naturalistic paradigm. The major differences among the approaches are coding schemes, origins of codes, and threats to trustworthiness. In conventional content analysis, coding categories are derived directly from the text data. With a directed approach, analysis starts with a theory or relevant research findings as guidance for initial codes. A summative content analysis involves counting and comparisons, usually of keywords or content, followed by the interpretation of the underlying context [25].

The information base of the study consisted of scientific works of foreign and domestic scientists on the topic of the article. The review of scientific sources of literature was carried out taking into account the recommendations of the Cochrane Society for PICO: P (population) - the population suffering from systemic autoimmune diseases; I (intervention) - pharmacotherapy, drugs INN Silymarin ATC code A05BA03; C (comparison) - comparison in research technology, innovative experimental study; 0 (outcomes) - research results. Based on a review of published qualitative strategy and management research, the author identifies highly innovative academic articles, that is, a study that demonstrates substantial novelty in every part of the research process. Author works through these articles in detail to demonstrate their novelty, highlighting concrete ways in which scholars have innovated three interconnected parts of the research process: data generation, data analysis, and presentation of findings. These principles are engaging in holistic innovation, being excruciatingly clear in the presentation of methods, developing theory and method together, and being reflexive in innovating methods. Our model demystifies the largely implicit process of innovating research methods [26-30].

Among the additional research methods used are regulatory, documentary, clinical and pharmacological, marketing, forensic and pharmaceutical and graphic. Microsoft Excel 2010 (descriptive characteristics: minimum and maximum value, average value) was used to process the results and determine the consistency between the studied parameters.

The research of the article is a fragment of research works of Lviv Medical Institute LLC on the topic "Improvement of the drug circulation system during pharmacotherapy on the basis of evidence-based pharmacy and forensic pharmacy, organization, technology, biopharmacy and pharmaceutical law" (state registration number 0120U105348, terms 2021-2026), Kharkiv Medical Academy of Postgraduate Education on "Improving the organizational and legal procedure for providing patients with drugs from the standpoint of forensic pharmacy, organization and management of pharmacy" (state registration number 0116U003137, terms 2016-2020) and "Pharmaceutical and medical law: integrated approaches to the system of drug circulation from the standpoint of forensic pharmacy and organization of pharmaceutical business" (state registration number D/21 U000031, terms 2021-2026).

\section{Results and Discussion}

At the first stage of the innovative experimental study, a marketing analysis of the INN Silymarin ATC code A05BA03 drugs range was conducted. During the marketing analysis of the range of drugs on the national market, an information array of marketing information about drugs was initially formed using the content analysis of official reference publications. Primary data for content analysis: drugs, which according to the normative-legal and documentary analysis as of June 2021 were registered, allowed for circulation on the territory of Ukraine, allowed for inclusion in pharmacotherapy of systemic autoimmune diseases. After summarizing the processed data, a marketing list of drugs was compiled according to INN Silymarin ATC code A05BA03, which has ten names of drugs (Table 1).

\begin{tabular}{|c|c|c|}
\hline No. & $\begin{array}{c}\text { Trade name/ } \\
\text { Manufacturer/ } \\
\text { Country }\end{array}$ & $\begin{array}{c}\text { Dosage form, weight, amount } \\
\text { per unit }\end{array}$ \\
\hline \multirow[t]{4}{*}{1} & 2 & 3 \\
\hline & \multirow{3}{*}{$\begin{array}{l}\text { Triosil/PJSC } \\
\text { "Fitopharm", } \\
\text { Ukraine }\end{array}$} & Tablets 22.5 mg N.30 \\
\hline & & Tablets 22.5 mg N.50 \\
\hline & & Tablets $22.5 \mathrm{mg}$ N.100 \\
\hline & \multirow{6}{*}{$\begin{array}{l}\text { Legalon/Madaus } \\
\text { GmbH, Germany }\end{array}$} & Capsules 140 mg N. 20 \\
\hline & & Capsules 140 mg N. 30 \\
\hline & & Capsules 140 mg N. 60 \\
\hline & & Capsules 70 mg N. 20 \\
\hline & & Capsules 70 mg N. 30 \\
\hline & & Capsules 70 mg N. 60 \\
\hline
\end{tabular}

Citation: Ihor Hayduchok. "Pharmacotherapy of Systemic Autoimmune Diseases in the Convention of the Covid-19 Pandemic: Search for Innovative Technologies in the Study". Acta Scientific Medical Sciences 5.9 (2021): 136-142. 
Pharmacotherapy of Systemic Autoimmune Diseases in the Convention of the Covid-19 Pandemic: Search for Innovative Technologies in the Study

139

\begin{tabular}{|c|c|}
\hline \multirow[b]{2}{*}{$\begin{array}{l}\text { Silibor forte/LLC } \\
\text { "Pharmaceuti- } \\
\text { cal company } \\
\text { "Zdorov'ya ", } \\
\text { Kharkiv, } \\
\text { Ukraine }\end{array}$} & Capsules 70 mg N. 20 \\
\hline & Capsules 70 mg N. 40 \\
\hline \multirow[b]{2}{*}{$\begin{array}{l}\text { Silibor max/LLC } \\
\text { "Pharmaceuti- } \\
\text { cal company } \\
\text { "Zdorov'ya", } \\
\text { Kharkiv, } \\
\text { Ukraine }\end{array}$} & Capsules 140 mg N. 20 \\
\hline & Capsules 140 mg N. 40 \\
\hline \multirow{4}{*}{$\begin{array}{l}\text { Silibor 35/LLC } \\
\text { "Pharmaceuti- } \\
\text { cal company } \\
\text { “Zdorov'ya ", } \\
\text { Kharkiv, } \\
\text { Ukraine }\end{array}$} & Coated tablets 35 mg N. 20 \\
\hline & Coated tablets 35 mg N. 25 \\
\hline & Coated tablets $35 \mathrm{mg} \mathrm{N.} 30$ \\
\hline & Coated tablets 35 mg N. 80 \\
\hline \multirow{2}{*}{$\begin{array}{l}\text { Fumart/JSC } \\
\text { "Farmak", } \\
\text { Ukraine }\end{array}$} & Capsules 50 mg N. 20 \\
\hline & Capsules 50 mg N. 30 \\
\hline $\begin{array}{c}\text { Carsil forte/ } \\
\text { JSC “Sopharma”, } \\
\text { Bulgaria }\end{array}$ & Hard capsules 90 mg N. 30 \\
\hline \multirow{3}{*}{$\begin{array}{c}\text { Darsil/PJSC } \\
\text { "Pharmaceutical } \\
\text { firm “Darnitsa", } \\
\text { Ukraine }\end{array}$} & Coated tablets 22,5 mg N. 30 \\
\hline & Coated tablets 22,5 mg N. 50 \\
\hline & Coated tablets $22,5 \mathrm{mg} \mathrm{N} .100$ \\
\hline $\begin{array}{c}\text { Carsil/JSC } \\
\text { "Sopharma”, } \\
\text { Bulgaria }\end{array}$ & Coated tablets 22,5 mg N. 80 \\
\hline $\begin{array}{l}\text { Hepabene/ } \\
\text { Merkle GmbH, } \\
\text { Germany }\end{array}$ & Hard capsules N. 30 \\
\hline
\end{tabular}

Table 1: Marketing list of drugs according to INN Silymarin ATC code A05BA03 for pharmacotherapy of patients with systemic autoimmune diseases.

For the next stage of the content analysis of drugs according to the INN Silymarin by manufacturers, primary data on the range and manufacturers of drugs of INN Silymarin ATC from the marketing list (Table 2) was selected and processed.

\begin{tabular}{|c|c|c|}
\hline No. & Manufacturer, Country & $\begin{array}{l}\text { Quantity } \\
\text { of drugs }\end{array}$ \\
\hline & PJSC “Fitopharm”, Ukraine & 1 \\
\hline & Madaus GmbH, Germany & 1 \\
\hline & JSC “Farmak”, Ukraine & 1 \\
\hline & $\begin{array}{c}\text { PJSC “Pharmaceutical firm” Darnytsia ", } \\
\text { Ukraine }\end{array}$ & 1 \\
\hline & Merkle GmbH, Germany & 1 \\
\hline & $\begin{array}{l}\text { JSC “Sopharma” (permission to produce a } \\
\text { series), Bulgaria }\end{array}$ & 2 \\
\hline & $\begin{array}{l}\text { LLC “Pharmaceutical company } \\
\text { "Zdorov'ya”, Ukraine }\end{array}$ & 3 \\
\hline & Total & 10 \\
\hline
\end{tabular}

Table 2: Primary data for content analysis by manufacturers from the marketing list of drugs by the INN Silymarin ATC code A05BA03.

In the pharmacotherapy of systemic autoimmune diseases, doctors use drugs of the INN Silymarin ATC code A05BA03 of the sevens manufacturers. The number of groups (three), the step of group (one) and the distribution by the range of drugs and manufacturers of the drugs of the INN Silymarin were further determined. Distribution of drugs with the INN Silymarin ATC code A05BA03 by range and manufacturers are given in table 3.

Based on the use of innovative experimental study technology on the range and manufacturers of drugs by the INN Silymarin ATC code A05BA03 (Table 3), found that in the first group of five manufacturers deliver to the hospital one drug each for pharmacotherapy of systemic autoimmune diseases. Among five manufacturers of drugs by the INN Silymarin the share of domestic is $60 \%$, foreign - $40 \%$. There is no balance, more offers and it makes sense to reduce the number of manufacturers for the hospital. In the second group, only one foreign manufacturer provides patients with two drugs by the INN Silymarin. The balance is more directed, doctors spend budget funds more expediently. In the third group, doctors prescribe one domestic manufacturer in the range of three drugs for pharmacotherapy by the INN Silymarin. The balance is even more directed, doctors spend the budget more expediently.

The obtained data indicate the possibility of a balance between supply and demand for patients and physicians among the range 


\begin{tabular}{|c|c|c|}
\hline No. & Manufacturer & $\begin{array}{c}\text { Range of } \\
\text { drugs }\end{array}$ \\
\hline \multicolumn{3}{|c|}{$1^{\text {st }}$ group } \\
\hline & PJSC “Fitopharm”, Ukraine & 1 \\
\hline & Madaus GmbH, Germany & 1 \\
\hline & JSC “Farmak”, Ukraine & 1 \\
\hline & $\begin{array}{l}\text { PJSC “Pharmaceutical firm” } \\
\text { Darnytsia “, Ukraine }\end{array}$ & 1 \\
\hline & Merkle GmbH, Germany & 1 \\
\hline \multicolumn{2}{|c|}{ Total } & 5 \\
\hline \multicolumn{3}{|c|}{$2^{\text {nd }}$ group } \\
\hline & $\begin{array}{l}\text { JSC “Sopharma” (permission to } \\
\text { produce a series), Bulgaria }\end{array}$ & 2 \\
\hline \multicolumn{2}{|c|}{ Total } & 2 \\
\hline \multicolumn{3}{|c|}{$3^{\text {rd }}$ group } \\
\hline & $\begin{array}{l}\text { LLC “Pharmaceutical company } \\
\text { “Zdorov'ya”, Ukraine }\end{array}$ & 3 \\
\hline & Total & 3 \\
\hline
\end{tabular}

Table 3: Distribution of drugs by the INN Silymarin ATC code A05BA03 by range and manufacturers based on innovative technology experimental study.

of drugs INN Silymarin ATC code A05BA03 manufacturers of the second and third groups.

Further statistical processing of the results of innovative experimental study technology was carried out. A discrete variation series (Table 4) and a polygon for the distribution of the obtained data (Figure 2) were developed.

\begin{tabular}{|l|c|c|}
\hline No. & $\begin{array}{c}\text { Quantity of } \\
\text { manufacturers }\end{array}$ & Frequency, $\mathbf{f}_{\mathrm{i}}$ \\
\hline & 5 & 5 \\
\hline & 1 & 2 \\
\hline & 1 & 3 \\
\hline
\end{tabular}

Table 4: Discrete variation series of drugs by the INN Silymarin ATC code A05BA03 based on innovative experimental study technology.

The discrete variation series is an ordered distribution of units of the study population into groups (according to the results of grouping using the Sturgess formula) according to a certain variable (range of manufacturers of drugs with INN Silymarin ATC code A05BA03).

Graphically discrete variation series of the studied drugs is presented in the form of a distribution polygon (Figure 2).

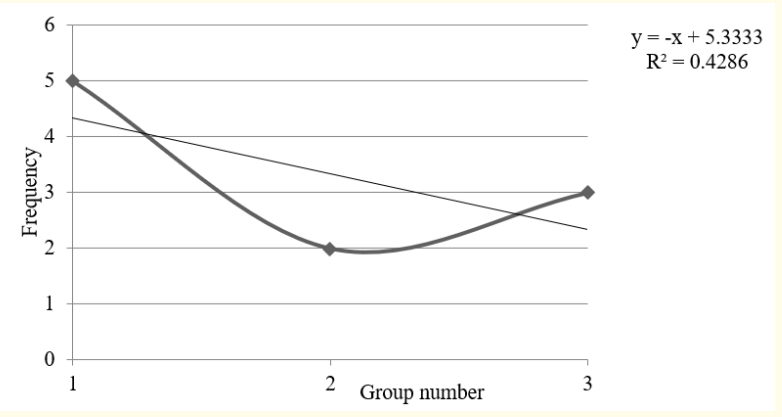

Figure 2: Polygon distribution range drugs with INN Silymarin ATC code A05BA03 based on innovative experimental study technology.

Polygon of distribution of drugs by the INN Silymarin ATC code A05BA03 confirms the previous conclusions: in the first group, the highest number of manufacturers $\left(f_{i}=5\right)$ provides pharmacotherapy with only one drug; in the second group $\left(f_{i}=2\right)$ one foreign manufacturer supplies two drugs; in the third group $\left(f_{i}=3\right)$ one domestic manufacturer supplies three drugs for pharmacotherapy of systemic autoimmune diseases. Innovative experimental study technology is performed from the standpoint of a formalized method of qualitative and quantitative analysis of documents, which allows to obtain a detailed view of the selected clinical and pharmacological group of drugs of INN Silymarin ATC code A05BA03 [31-33].

Innovative experimental technologies in the study of pharmacotherapy of systemic autoimmune diseases are the use of content analysis as an additional method in the justification of pharmacotherapy, drug selection, method of financing.

\section{Conclusion}

Conducted an innovative experimental study of pharmacotherapy of systemic autoimmune diseases using content analysis 
on the example of drugs by the INN Silymarin ATC code A05BA03 in healthcare facilities (hospitals, clinics, pharmacies). The analysis allows obtaining a complete description of the balance of "supply and demand" between the range and manufacturers of drugs INN Silymarin ATC code A05BA03, approved for use. Doctors have a choice of the appropriate drug and the manufacturer that corresponds to the social personalized pharmacotherapy. Content analysis is a widely used innovative method of analysis of pharmacotherapy schemes for systemic connective tissue diseases.

An innovative experimental study is that the content analysis is based on the creation of a neutral framework for the classification of efficacy descriptions of drugs by the INN Silymarin ATC code A05BA03. The use of innovative experimental methods for personalized drug selection for patients with systemic autoimmune diseases in a pandemic of coronavirus infection is promising and socially justified.

Author hopes it serves to orient and encourage a more creative use of innovative experimental methods and technologies in future studies.

\section{Gratitude}

Author thanks the administration, doctors and nurses of the Lviv Medical Institute LLC, Kharkiv Medical Academy of Postgraduate Education, State Institution "Kundiiev Institute of Occupational Health of the National Academy of Medical Sciences of Ukraine", Danylo Halytsky Lviv National Medical University, for their help and support when working with clinical protocols and drugs during a qualitative innovative study.

\section{Conflict of Interests}

There is no conflict of interest to disclose for each author.

\section{Bibliography}

1. Beketova TV., et al. "COVID-19 in a patient with ANCA-associated systemic vasculitis, receiving anti-B cell therapy (rituximab)". Rheumatology Science and Practice 58.4 (2019).

2. Shapovalova VO., et al. "Coronavirus disease pandemia 2019: growth of epidemic dangers". Acta Scientific Pharmaceutical Sciences 4.7 (2020): 61-68.

3. Hayduchok IG., et al. "Control regime of antibacterial drugs for pharmacotherapy of coronavirus disease (COVID-19) among patients with dual disorders". An Information Letter About Innovations Ukrmedpatentinform of the Ministry of Health of Ukraine. Kyiv: Ukrmedpatentinform of the Ministry of Health of Ukraine 230.2020 (2020): 6.

4. Hayduchok IG., et al. "Control regime of drugs for pharmacotherapy of coronavirus disease (COVID-19) among patients with systemic diseases". An information letter about innovations Ukrmedpatentinform of the Ministry of Health of Ukraine. Kyiv: Ukrmedpatentinform of the Ministry of Health of Ukraine 225.2020 (2020): 6.

5. Parnes 0. “Autoimmune disease". The Lancet 367 (2018): 389.

6. Yemchenko YO., et al. "Analysis of the incidence and prevalence of psoriasis in Ukraine and Poltava region". Bulletin of VDNZU “Ukrainian Medical Dental Academy” 14.3 (2014): 72-76.

7. Hayduchok IG., et al. "Control regime of drugs for pharmacotherapy vasculitis of Shenlein-Genoch". An Information Letter About Innovations Ukrmedpatentinform of the Ministry of Health of Ukraine. Kyiv: Ukrmedpatentinform of the Ministry of Health of Ukraine 64.2021 (2021): 7

8. Takakubo K., et al. "Immune-regulatory mechanisms in systemic autoimmune and rheumatic diseases". Clinical and Developmental Immunology 37.3 (2012): 341-346.

9. Hayduchok IG., et al. "Control regime of drugs for pharmacotherapy Rheumatoid arthritis". An information Letter About Innovations Ukrmedpatentinform of the Ministry of Health of Ukraine. Kyiv: Ukrmedpatentinform of the Ministry of Health of Ukraine 36.2021 (2021): 7.

10. Shapovalov V. "Use of innovative technologies in pharmacotherapy with target nanotherapy on the principles of evidence-based medicine and pharmacy". Actual Problems of Medicine and Pharmacy 1.1-2 (2020).

11. Anderson PD., et al. "The Forensic Pharmacist. Drug Injury: Liability, Analysis, and Prevention". Hardcover 23 (2017): 761770 .

12. Shapovalov (Jr.) V., et al. "Forensic and pharmaceutical study of the presence of a causal link between the degree of alcohol 
abuse and qualification level of the respondents". Pharmacia 66.3 (2017): 31-39.

13. Shapovalova V. "System of drugs circulation based on medical and pharmaceutical law". Actual Problem of Medicine and Pharmacy 1.1-2 (2020).

14. Hayduchok I., et al. "Organizational and legal measures of state control of reforming and modernizing the health care on principles of pharmaceutical and medical law". Actual Problems of Medicine and Pharmacy 1.1-2 (2020).

15. Shapovalova VA., et al. "Organizational and legal evaluation of availability of medicines' circulation for cancer patients". Pharmacia 65.2 (2018): 17-22.

16. Hayduchok I. "Pharmacotherapy of immunopathological syndromes among patients with systemic lupus erythematosus based on ABC/VEN analysis". Acta Scientific Medical Science 5.6 (2021): 67-73.

17. Hayduchok I. "Pharmacotherapy of Systemic Vasculitis Combined with Cryoglobulinemic Syndrome using Pharmacoeconomic Approaches". Global Journal of Health Science 13.7 (2021): 78-88.

18. "Management Science for Health. Managing Medicines Selection". Managing Access to Medicines and Health Technologies. USA: Arlington (2012): 16.1-16.15.

19. Shapovalov (Jr.) V., et al. "Concerning the importance of forensic and pharmaceutical researches to improve patients' accessibility to medicines". Pharmacia 65.2 (2017): 23-29.

20. "ATC-classification". Compendium on-line.

21. Shapovalova VA., et al. "Forensic pharmacy: some risk factors in the formation of addictive health disorders". Acta Scientific Pharmaceutical Science 4.1 (2021): 7-12.

22. Shapovalova VO., et al. "Content analysis of pharmacies in Ukraine, which produce extemporaneous drugs". Public Health 6.3-4 (2017): 77-83.

23. Shapovalova VO. et al. "Content analysis of alcohol circulation in healthcare facilities at the stage of budget procurement". Copyright No. 79456 (Ukrainian).
24. Gudzenko AA and Osyntseva AA. "Shapovalova V.O. Content analysis of the circulation of alcoholic drugs by dosage form and registration certificates". Copyright 79473 (Ukrainian). Publ. 06/01/18.

25. Hsieh Hsiu-Fang., et al. "Three approaches to qualitative content analysis". Qualitative Health Research 15.9 (2000): 12771288.

26. "Ministry of healthcare of Ukraine official site".

27. "National list of basic medicines". Resolution of the Cabinet of Ministers of Ukraine 333 (2009).

28. "On approval of the twelfth issue of the State formulary of medicines and ensuring its availability". Order of the Ministry of Health of Ukraine 1075 (2020).

29. Shapovalov (Jr.) V., et al. "Organizational and legal analysis of the pharmaceutical provision for the most common diseases of society". International Journal of Pharmaceutical Sciences Review and Research 51.18 (2018): 118-124.

30. Le JK., et al. "The Practice of innovating research methods". Sage Journal (2020).

31. Davis J. "Content analysis of efficacy descriptions on branded pharmaceutical websites". Journal of Medical Marketing 12.4 (2012): 211-220.

32. Awaisu A., et al. "Research designs and methodologies related to pharmacy practice". Encyclopedia of Pharmacy Practice and Clinical Pharmacy (2019): 7-21.

33. Christy J., et al. "Content analysis of internet marketing strategies: how pharmaceutical companies communicate about contraceptives with consumers online". Journal of Medical Internet Research (2009).

\section{Volume 5 Issue 9 September 2021 (C) All rights are reserved by Ihor Hayduchok.}

